\title{
SDS-PAGE Electrophoretic Property of Human Chorionic Gonadotropin (hCG) and its $\beta$-subunit
}

\author{
Lay-Harn Gam, Aishah Latiff \\ ${ }_{2}^{1}$ School of Pharmaceutical Sciences, University Sciences of Malaysia, 11800 Penang, Malaysia. \\ ${ }^{2}$ Doping Control Centre, University Sciences of Malaysia, 11800 Penang, Malaysia.
}

Corresponding address: Dr Lay-Harn Gam, School of Pharmaceutical Sciences, Universiti Sains Malaysia, 11800 Minden, Pulau Pinang, Malaysia. Fax: 604-6570017. e-mail: layharn@usm.my

Received: 2005.03.15; Accepted: 2005.04.27; Published: 2005.05.10

The microheterogeneity property of hCG with regards to its sialic acid contents resulted in variable mobility of the glycoprotein in SDS-PAGE. The intact hCG molecule is composed of two dissimilar subunits, namely $\alpha-$ and $\beta-$ subunits. The identification of hCG bands in SDS-PAGE was accomplished by the immunoblotting experiment, whereby the antibody directed toward the specific region of $\beta$-subunit of hCG was used. The data shows that the different mobility of intact hCG was attributed to the different degree of desialylation of the glycoprotein. Nevertheless, unlike the intact hCG, the mobility of its $\beta$-subunit was not affected by its variety sialic acid content. This characteristic of $\beta-h C G$ is beneficial when semi-quantification of total hCG is required. Quantification of hCG using the HPLCreversed phase $\mathrm{C}_{18}$ analytical column is not possible as the glycoprotein was eluted in multiple fractions at different retention times. The identification of denatured hCG (HPLC eluted fractions) was carried out by immunoblotting experiment whilst immunoassay technique failed to detect its presence in any fraction.

Key words: Human Chorionic Gonadotropin, heterogeneity, SDS-PA GE, immunoblotting

\section{Introduction}

Human chorionic gonadotropin (hCG) is a glycoprotein hormone that is synthesized by the syncytiotrophoblast cells of placenta [1]. The hormone is released in the first few weeks of pregnancy. During the early days of pregnancy, hCG prolongs the life of corpus luteum and also stimulates secretion of estrogen and progestine by the corpus luteum to prevent the decline in luteal function that normally occurs in infertile menstrual cycle $[2,3]$. Between the $7^{\text {th }}$ to 12 week of pregnancy, the plasma hCG rises to extremely high levels where approximately $11,000-289,000 \mathrm{mIU} / \mathrm{ml}$ of hCG were released. This is followed by the decline during the last two trimesters [4]. hCG was first found in human pregnancy urine in 1927 [5] and its presence continues to be the basis of pregnancy tests. hCG is one of the hormones that was screened during doping analysis, the misused of hCG by male athletes is to induce the secretion of testosterone from the testis [6]. A confirmatory and quantitative HPLC-tandem mass spectrometry method for hCG was suggested by the author [7].

Human chorionic gonadotropin (hCG) is composed of two dissimilar subunits [8], namely $\alpha$ - and $\beta$-subunits. The subunits are held together primarily by hydrophobic bonding [9]. The molecular weight of intact hCG, ahCG and $\beta \mathrm{hCG}$ are approximately 36.7, 14.5 and $22.2 \mathrm{kDa}$, respectively. It has been estimated that $30 \%$ of the total weight of hCG is contributed by the carbohydrate content which accounts for the heterogeneity property of hCG. There are a total of 8 carbohydrate attachment sites in a hCG molecule, two are at the $\alpha \mathrm{hCG}$ and the rest are at the $\beta$ hCG. The carbohydrate content of hCG is composed of $10-11 \%$ of neutral sugar, $10-11 \%$ amino sugar and $8-9 \%$ of sialic acids or also known as $\mathrm{N}$-acetylneuraminic acids (1). The sialic acid which resides at the terminal portion of carbohydrate side chain varies most among different preparations of hCG, and appears to be closely correlated with the biological activity of the hormone [10] but not affecting its immunological activity [11]. Kessler, et al. $[12,13]$ cited that each carbohydrate moiety contains two attached sialic acid groups; giving rise to a total of 16 sialic acids per hCG molecule. Nevertheless, the sialic acid content vary from one hCG preparation to the other, and this is clearly shown in the pI values of hCG. The pI values give an indication of the sialic acid content in the molecules; the greater number of sialic acid on the hCG leads to a greater ionization constant and hence lower the pI value. In this study, we report the variable electrophoretic mobility of hCG attributed to the different degree of desialylation of the hCG. Furthermore, the activity of denatured hCG after reversed phase chromatographic separation was recovered by immobilizing the denatured hCG molecules on the nitrocellulose membrane via Western blotting experiment.

\section{Materials and Methods}

\section{Chemicals}

Human chorionic gonadotropin (lot CG 10) prepared from pooled pregnancy urine, $\beta$-subunit of hCG $(\beta h C G)$, Anti-Rabbit IgG alkaline phosphatase conjugate, acrylamide/bis solution, rabbit anti-hCG, premixed BCIP/NBT solution, Sodium dodecyl sulphate, TEMED, Tween 20, BSA, glycine, glycerol, Sodium Chloride, Magnesium Chloride and Tris-base were purchase from Sigma (St Louise, MO, USA). Silver staining kit, Enzymatic deglycosylation kit were purchased from BIORAD (Regents Park, AUS). 


\section{Sodium dodecyl sulphate-polyacrylamide gel electrophoresis (SDS-PAGE)}

SDS-PAGE was performed as described by Laemmli [14] using and $12 \%$ polyacrylamide gel in a vertical slab gel apparatus (Hoefer Scientific Instrument)

The proteins were prepared in non-reduced (intact) and reduced forms. For the preparation of non-reduced protein samples, sample buffer $(10 \%$ of the total volume of the sample) was added to the protein sample and then vortex for 2 minutes. For the preparation of reduced protein samples, reduced sample buffer $(5 \% \quad \beta$ mercaptoethanol in sample buffer) was added to the protein samples ( $10 \%$ of the total volume of the sample). The mixture was vortexed and then boiled at $100^{\circ} \mathrm{C}$ for 5 minutes. Electrophoresis was performed using vertical electrophoresis slab gel apparatus (Hoefer Scientific Instrument) at a constant voltage of 173 volts when samples were in the stacking gel. When the dye front reached the resolving gel, voltage was increased to 245 volts. The run was stopped when the dye front was 2 to 3 $\mathrm{mm}$ away from the bottom edge of the gel. The gel was then silver stained using the commercial silver staining kit.

\section{Western Blotting}

Western blotting was performed according to the modified method of Towbin, et al. [15]. After electrophoresis, the gel was soaked in cold transfer buffer (0.192 M glycine; $0.025 \mathrm{M}$ tris, $\mathrm{pH} 8.3$ and $0.0013 \mathrm{M}$ SDS) for 1 hour to remove SDS and any excess electrode buffer. A sheet of nitrocellulose membrane (pore size $0.45 \mu \mathrm{m}$ ) was cut $(15 \times 15 \mathrm{~cm})$ and labeled with a soft pencil to identify the gel and the orientation of the membrane. The membrane was then slowly immersed into transfer buffer by sliding it at a $45^{\circ}$ angle and then allowed to soak for 1 hour. To avoid contamination, forceps and gloves were used when handling the membrane.

Blotter papers (Advantec, Japan) were cut to the dimension of the gel and then completely saturated by soaking the papers in transfer buffer. When blotter paper, gel and membrane have been assembled into the correct orientation, pressure was applied until adhesive contact was made between the membrane and gel. Proteins on the gel were electrophoreticaly transferred to the nitrocellulose menbrane using the TE 70 Semiphor semi-dry transfer unit (Hoefer Scientific Instrument) at $134 \mathrm{~mA}$ for 3 hours. After the transfer, the transblot cassette was disassembled and the gel was stained to give an indication that the transfer had completed.

The nitrocellulose membrane was gently rocked in blocking buffer [3\% (w/v) BSA in TNT buffer] for 2 hours at room temperature to block unoccupied sites. It was then washed thrice (10 minutes each) in the wash buffer [0.1\% (w/v) BSA in TNT buffer]. The membrane was then incubated in $100 \mathrm{ml}$ of rabbit anti-hCG antibody (Dako) at 1:5000 dilution in antibody diluent buffer $[0.1 \%$ (w/v) BSA, $0.1 \%$ Tween 20, $0.02 \% \mathrm{NaN}_{3}$ in TNT buffer] overnight at $25^{\circ} \mathrm{C}$ in a rocking motion. The membrane was washed 3 times with wash buffer and incubated in $100 \mathrm{ml}$ of alkaline phosphatase-conjugated anti-rabbit antibody (diluted 1:2000) for two and a half hours at room temperature. The membrane was then washed twice (10 minutes each) with a large volume of Buffer 1 (0.1 M Tris- $\mathrm{HCl}, 0.15 \mathrm{M} \mathrm{NaCl}, \mathrm{pH} 7.5)$ and once with Buffer 3 for 10 minutes $(0.1 \mathrm{M}$ Tris-HCl, $0.1 \mathrm{M} \mathrm{NaCl}, 50$ $\mathrm{mM} \mathrm{MgCl}_{2}, \mathrm{pH}$ 9.5). Finally, $10 \mathrm{ml}$ of substrate [containing NBT (nitroblue tetrazolium chloride) and BCIP (5-bromo-4-chloro-3-indolyphosphate-p-toluidine salt) (Sigma) was added. The membrane was rocked for 20 minutes and the reaction stopped by washing the membrane with Buffer 4 (20 mM Tris, $0.5 \mathrm{mM} \mathrm{Na} 2$ EDTA, $\mathrm{pH}$ 7.5). The membrane was then air dried and photographed.

\section{Neuraminidase digestion of sialic acid}

$100 \mu \mathrm{g}$ of hCG was dissolved in $200 \mu \mathrm{l}$ of $20 \mathrm{mM}$ sodium phosphate buffer $(\mathrm{pH}$ 6) and $1 \mathrm{mIU}$ of neuramidase in $50 \mu \mathrm{l}$ of the same buffer was added. The mixture was incubated for 20 hours at $37^{\circ} \mathrm{C}$ to remove sialic acid.

\section{Analysis of hCG using reversed-phase HPLC separation}

A volume of $50 \mu \mathrm{l}$ of hCG purchased from Sigma was injected into a Supelcosil wide pore columns $(25 \mathrm{~cm} \mathrm{x}$ $4.6 \mathrm{~mm}$ ID, $5 \mu \mathrm{m}$ particles, $300 \AA \AA$ ) (Supelco) connected to a HPLC (Hewlett Packard, Series 1100). The HPLC flow rate was set at $1 \mathrm{ml} / \mathrm{min}$ and the gradient used was $5 \%$ to $60 \%$ B in 120 minutes and held constant at $60 \%$ B for 10 minutes. The detection wavelength was set at $220 \mathrm{~nm}$ (UV range).

\section{Results and Discussion}

In our present study, hCG purchased from Sigma was used as a reference standard in order to identify hCG band amongst many other urinary protein bands found in pregnancy urine. The SDS-PAGE profile is shown in Figure 1. Lane 2 shows the protein profile of hCG from Sigma, whereby many protein bands were detected and hence it did not serve as a good hCG marker. Identification of hCG by referring to its molecular weight was also not possible as the carbohydrate content of the hormone altered its mobility in SDS-PAGE.

Western blotting experiment was carried out to identify hCG band by means of antibody-antigen interaction. Antibody against the $\beta$-subunit of hCG was chosen to avoid cross reaction with LH, FSH and TSH hormones which share the common $\alpha$-subunit with hCG. The antibody recognizes both the free $\beta h C G$ and the hCG dimer (intact hCG molecule).

The Western Blotting result is shown in Figure 2. Samples of purified hCG dimer were obtained from Sigma whereas the non-purified hCG was obtained from raw pregnancy urine without further treatment. The samples were prepared in reduced and non-reduced forms.

Purified $\beta$ hCG purchased from Sigma was used as $\beta$ hCG standard. Both reduced and non-reduced form of purified $\beta$ hCG were migrated as a single band at 35.2 $\mathrm{kDa}$. In the lanes (lanes $8 \& 12$ ) of non-reduced form of hCG dimer from raw pregnancy urine, two bands were picked up by the antibody at 43.5 and $35.2 \mathrm{kDa}$. Upon reduction, the $43.5 \mathrm{kDa}$ band was reduced in intensity coincide with the increase in intensity of the $35.2 \mathrm{kDa}$ band. The $35.2 \mathrm{kDa}$ band was identified earlier as $\beta \mathrm{hCG}$ whereas the $43.5 \mathrm{kDa}$ band was identified to be the hCG dimer, which was dissociated to form its individual subunits upon reduction. Non-reduced purified hCG (lane 3) was detected as multiple bands at 43.5, 38.5 and $35.2 \mathrm{kDa}$, besides the 43.5 and $35.2 \mathrm{kDa}$ bands which were discussed earlier, the 38.5 band is identified as hCG dimer band that contains different quantity of sialic acid as compared to the hCG dimer at $43.5 \mathrm{kDa}$ band. This is 
confirmed by the bands shown in lane 6 , which is the partially desialylated hCG preparation. The bands that were detected in non-reduced partially desialylated-hCG sample were 43.5, 38.5, 29.45 and $20.85 \mathrm{kDa}$, which after being reduced, migrated as single band at $35.2 \mathrm{kDa}$ (Figure 3). Following reduction, all the different forms of hCG dimer dissociated into a single band at $35.2 \mathrm{kDa}$ (Figure 2, lane 2), which was identified as $\beta$ hCG. Nevertheless, upon complete desialylation, the migration of hCG was non-heterogenous whereby, a single band was detected for hCG dimer at $29.45 \mathrm{kDa}$ (Figure 4).

Different in electrophoretic mobility of hCG in SDSPAGE was reported by Manjunath \& Sairam [16], whom suggested that the heterogenous property of hCG was attributed to its different sialic acid content. Our data indicates that variation in electrophoretic mobility with regards to varying sialic acid content is only applicable to hCG dimer. However, $\beta$ hCG did not exhibit differential electrophoretic mobility although its sialic acid content may vary. Throughout the experiment, $\beta$ hCG exists as single band in SDS-PAGE. The consistent mobility of $\beta$ hCG shown in this study is beneficial when semiquantification of hCG is required. The used of hCG by male athletes has been banned by the IOC in 1983. The level of hCG found in healthy male urine is $1 \mathrm{mIU} / \mathrm{ml}$ or less [17]. Furthermore, hCG is also secreted in male with malignant diseases, whereby high concentration $(>1000 \mathrm{mIU} / \mathrm{ml})$ of hCG can be detected in serum and urine of the patients [18]. Thus, quantification of hCG is critical in order to evaluate the true positive cases of doping of hCG $(>10 \mathrm{mIU} / \mathrm{ml})[19]$.

In another study, quantification of hCG was carried out by using HPLC analytical method. Purified hCG dimer purchased from Sigma was subjected to reversedphase chromatographic separation, the chromatogram monitored at $220 \mathrm{~nm}$ wavelength is shown in figure 4 . Within the 130 minutes run time, six peaks were detected at 5.13, 20.9, 37.0, 83.5 and 121.5 minutes retention times. Eluent from each peak was collected in fraction, the fractions were then dried under Nitrogen and reconstituted in $10 \mathrm{mM}$ Phosphate buffer $(\mathrm{pH} 7.2)$, the final $\mathrm{pH}$ was readjusted to 7.2 before assaying using hCG immunoassay kit by Abbot IMX. None of the fractions collected shows the presence of immunoreactive hCG. The lack of immunoreactivity was due to the lost of hCG activity during reversed phase separation which occurred at $\mathrm{pH} 2$ [20].

Hence, Western blotting experiment was carried out to determine hCG in the eluent collected. Activity of hCG which could not be detected previously by immunoassay method is detectable in Western blotting experiment (figure 5). In Western blotting, denatured hCG is immobilized on a membrane surface, the immobilization of hCG probably enhance the binding of antibody to hCG's antigenic region. Therefore as compare to the immunoassay technique (nonimmobilized), Western blotting may serve as a better tool for detecting denatured proteins.

Upon chromatographic separation, hCG was eluted in multiple fractions at 5.13, 21 and 37 minutes retention. This observation is in accord with other authors [21, 22, 23] whom worked on other types of proteins. Simpson and Moritz [24] suggested that silanophilic interactions due to residual silonol groups remaining on the column bonded phase may be responsible for the irregular elution pattern of glycoprotein when analyzed using
HPLC-reserved phase. Most of the hCG molecules were dissociated into their individual subunits. Figure 6 (lane 1) shows that fraction of hCG eluted at $5.3 \mathrm{~min}$ is mainly made up of $35.2 \mathrm{kDa}$ band, which is known as $\beta \mathrm{hCG}$. Whilst, three hCG bands were detected in the fraction collected at 20.9 minute (lane 4), these bands were at 35.4, 21.3 and $17.45 \mathrm{kDa}$. Besides the band at 35.2, the other two bands are probably the hCG dimer that differ in sialic acid contents. Two bands at 35.2 and $21.3 \mathrm{kDa}$ were detected in fraction collected at 37.0 minute (lane 6), the $21.3 \mathrm{kDa}$ band is again suspected to be hCG dimer as mentioned earlier. Nevertheless, the data reveals that analysis of hCG by HPLC-reverse phase is not suitable for quantification of hCG since the glycoprotein is eluted at multiple retention times.

\section{Conclusion}

The mobility of hCG dimer in SDS-PAGE was affected by its sialic acid content. In this study, hCG dimer was detected to migrate at different electrophoretic mobilities. Upon reduction, hCG dimer is completely dissociated into its subunits and its $\beta$-subunit ( $\beta \mathrm{hCG}$ ) is migrated as single band at $35.2 \mathrm{kDa}$. These characteristics of hCG when analyzed using SDS-PAGE can be used as the basis for semi-quantification of hCG in doping analysis. Furthermore, both purified and raw $\beta$ hCG also shown none variable migration in SDS-PAGE. Analysis of hCG using HPLC-reversed phase column resulted in multiple elution of hCG at different retention times. Therefore, HPLC analytical method is found not suitable for quantification of hCG.

\section{Acknowledgement}

We thank the Malaysian Ministry of Youth and Sport and the University Short Term Grant for providing the infrastructures and financial supports to this project.

\section{Conflict of interest}

The authors have declared that no conflict of interest exists.

\section{References}

1. Canfield RE, Morgan FJ, Kammerman S, Bell J J, Agosto FM. Studies of human chorionic gonadotropin. Rec Progr Horm Res 1971;27:121-164

2. Ross GT, Cargille CM, Lipsett MB, Rayford RL, Narshall JR, Strott CA, Rodbard D. Pituitary and gonadal hormones in women during spontaneous and induced ovulatory cycles. Rec Progr Horm Res 1970;26:1-62.

3. Vande Wiele RL, Bogumil J, Dyrenfurth I, Ferin M, Jewelewicz R, Warren M, Rizkallah T, Mikhail G. Mechanisms regulating the menstrual cycle in women. Rec Progr Horm Res 1970;26:63-103.

4. Braunstein GD, Karow WG, Gentry WC, Rasor J, Wade ME. First trimester chorionic gonadotropin measurements as an aid in the diagnosis of early pregnancy disorders. Am J Obstet Gynecol 1978; 131: 225-232.

5. Pierce JG, Parsons TF. Glycoprotein hormones: Structure and function. Ann Rev Biochem. 1981;50: 4459-4465.

6. De Boer D, De Jong EG, Rossum Wan JM, Moes RAA. Doping control of testosterone and hCG: a case study. Int J Sports Med 1991;12: 46-51.

7. Gam LH, Tham SY, Aishah L. Immunoaffinity extraction and tandem mass spectrometric analysis of human chorionic gonadotropin in doping analysis. J Chromatogr B 2003;792:187196.

8. Canfield RE, Birken S, Morse JH, Morgan FJ. Human Chorionic Gonadotroin. In: Parsons JA, ed. Peptide Hormones. The Macmillan press LTP. 1976:299-385. 
9. Vaitukaitis JL, Ross GT, Braunstein GD, Rayford PL. Gonadotropins and their subunits: basic and clinical studies. Recent Prog Horm Res 1976;32:289-298.

10. Van Hall H, Goverde BC, Schuurs AHWM, de Jager E, Matthijsen RM, Jorman JDH. Characterization and immunochemical properties of hCG. Nature 1966;212:261.

11. Van Hall EV, Vaitukaitis JL, Ross GT, Hickman JW, Ashwell G. Immunological and biological activity of hCG following pregressive desialylation. Endocrinol 1971;88:456.

12. Kessler M., Mise T, Chai RD, Bahl OP. Structure and location of O-glycosidic carbohydrate units of hCG. J Biol Chem 1979;254: 7904-7908.

13. Kessler MJ, Reddy MS, Shah RH, Bahl OP. Structure of Nglycosidic carbohydrate units of hCG. J Biol Chem 1979;254: 7901-7903.

14. Laemmli UK. Cleavage of structural proteins during the assembly of the heat of bacteriophage T4. Nature 1970;227:680-685.

15. Towbin HT, Stachelin T, Gordon T. Electrophoretic transfer of protein from polyacrylamide gels to nitrocellulose sheets: Procedure and applications. Proc Natl Acad Sci USA. 1979;76:4350-4354.

16. Marijunath P, Sairam MR. Biochemical, biological and immunological properties of chemically deglycosylataed hCG. Biol Chem 1982;25:7109-7115.

17. Alfthan H, Hagland C, Dabek J, Stenman U-H. Concentration of $\mathrm{hCG}, \beta \mathrm{hCG}$ and $\mathrm{c} \beta \mathrm{hCG}$ in serum and urine of non-pregnant women and men. Clin Chem 1990;38: 1981-1987.

Figures

Figure 1: SDS - PAGE for purified and urinary hCG separation. Lane 1: protein molecular weight markers; lane 2: purified hCG purchased from Sigma; lane 3: non-reduced urine from pregnant women; lane 4: reduced blank urine; lane 5: reduced urine from pregnant women. The arrows indicated the expected $\beta$ hCG bands.

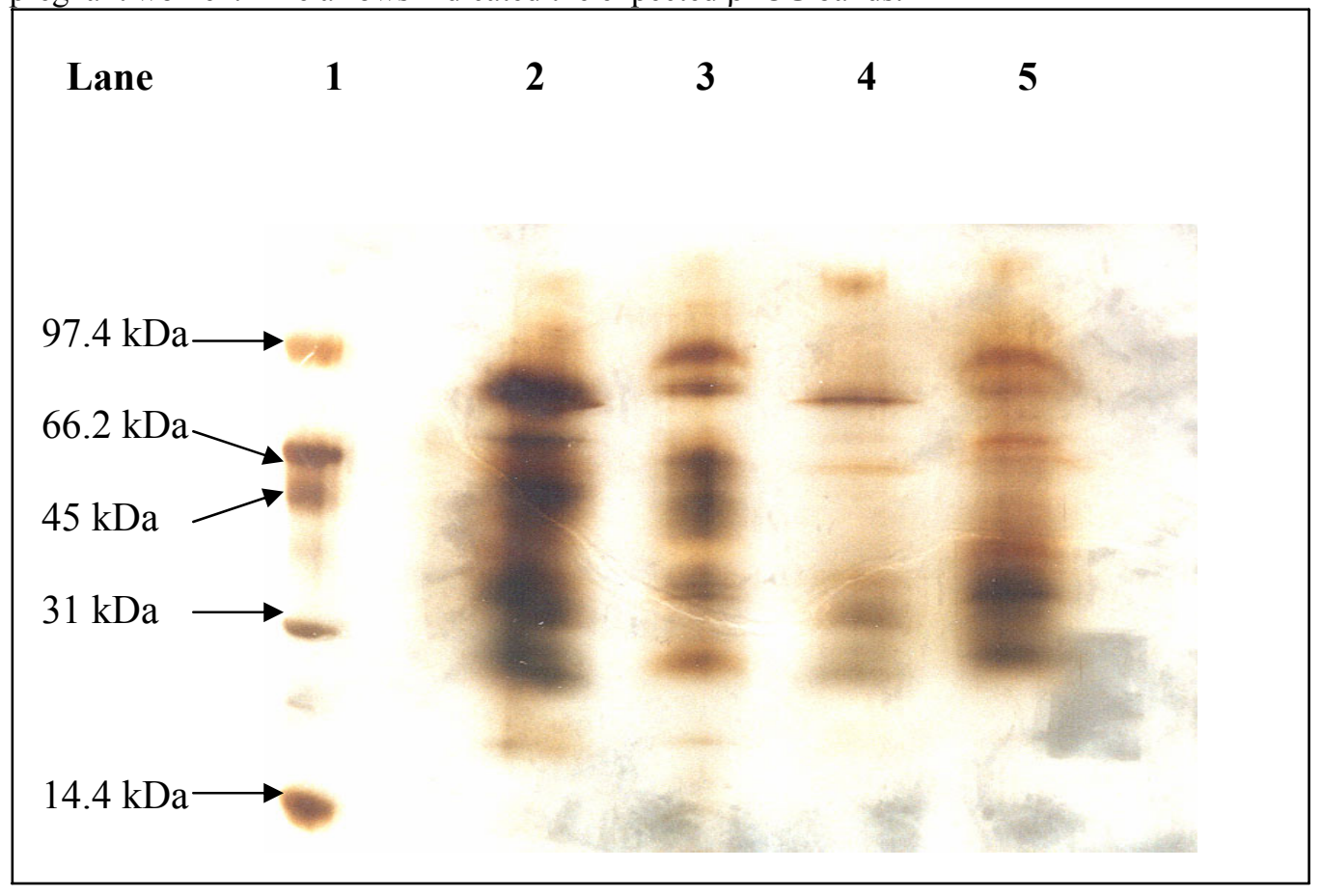

18. Stenman U-H, Alfthan A, Ranta T, Vartianen E, Jalkanen J, Seppala M. Serum levels of hCG in nonpregnant women and men are modulated by gonadotropin-releasing hormone and sex steroids. J Clin Endocrinol Metab 1987;64:730-736.

19. Laidler P, Cowan DA, Hider RC, Kicman T. New decision limits and quality-control material for detecting hCG misuse in sports. Clin Chem 1994;40:1306-1311.

20. Wilks JW, Butler SS. Biologic activity of human chorionic gonadotropin following reversed-phase high-performance liquid chromatography. J Chromatogr 1984;298:123-130.

21. Sander LC, Field LR. Effect of eluent composition on thermodynamic properties in high-performance liquid chormatography. Anal Chem 1980;52:2009-2013.

22. Bij KE, Harvath WR, Nahun A. Surface silanols in silica-bonded hydrocarbon-aqueous stationary phases. II. Irregular retention behaviour and effect of silanol masking. J Chromatogr 1981;203: 65-72.

23. Hearn MTW, Grego B. HPLC of amino acids, peptides and proteins. Organic solvent modifier effects in the separation of unprotected peptides by reversed-phase liquid chromatography. J Chromatogr 1981;218: 497-502.

24. Simpson RJ, Moritz RL. Chromatography of proteins at high organic solvent concentration: an inverse-gradient reversed-phase HPLC method for preparing sample for microsequence analysis. In: Mant CT, Hodges RS, eds. HPLC of peptides and proteins: separation, analysis, and confirmation. CRC press. 1991:399-408. 
Figure 2: Immunoblot of hCG; lane 1: protein molecular weight markers, lane $2 \&$ 3: reduced (the arrow indicates $\beta$ hCG band) $\&$ non-reduced hCG (Sigma), lane $4 \&$ 5: reduced \& non-reduced $\beta \mathrm{hCG}$, lane 6: desialylated hCG, lane $7 \&$ 8: reduced \& non-reduced pregnancy urine, lane $9 \& 10$ are not loaded with any sample, lane $11 \& 12$ : reduced \& non-reduced pregnancy urine.

\section{$\begin{array}{lllllllllllll}\text { Lane } & 1 & 2 & 3 & 4 & 5 & 6 & 7 & 8 & 9 & 10 & 11 & 12\end{array}$}

kDa

$66.2 \longrightarrow$
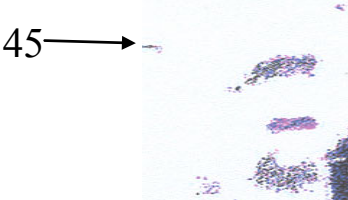

31

21.5

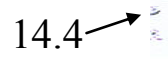

Figure 3: Immunoblot for $\beta$ hCG; lane 1: $\beta$ hCG standard, lane 2: reduced partially desialyted hCG.

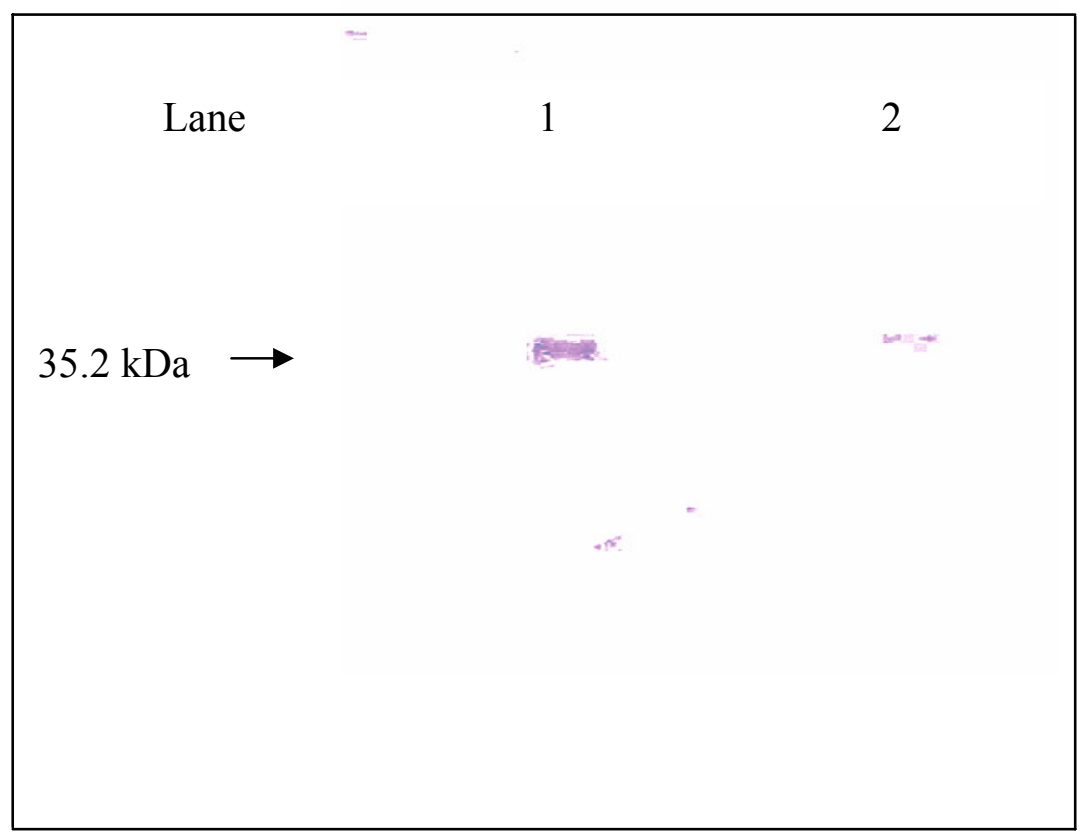


Figure 4: Immunoblot of fully desialylated hCG.

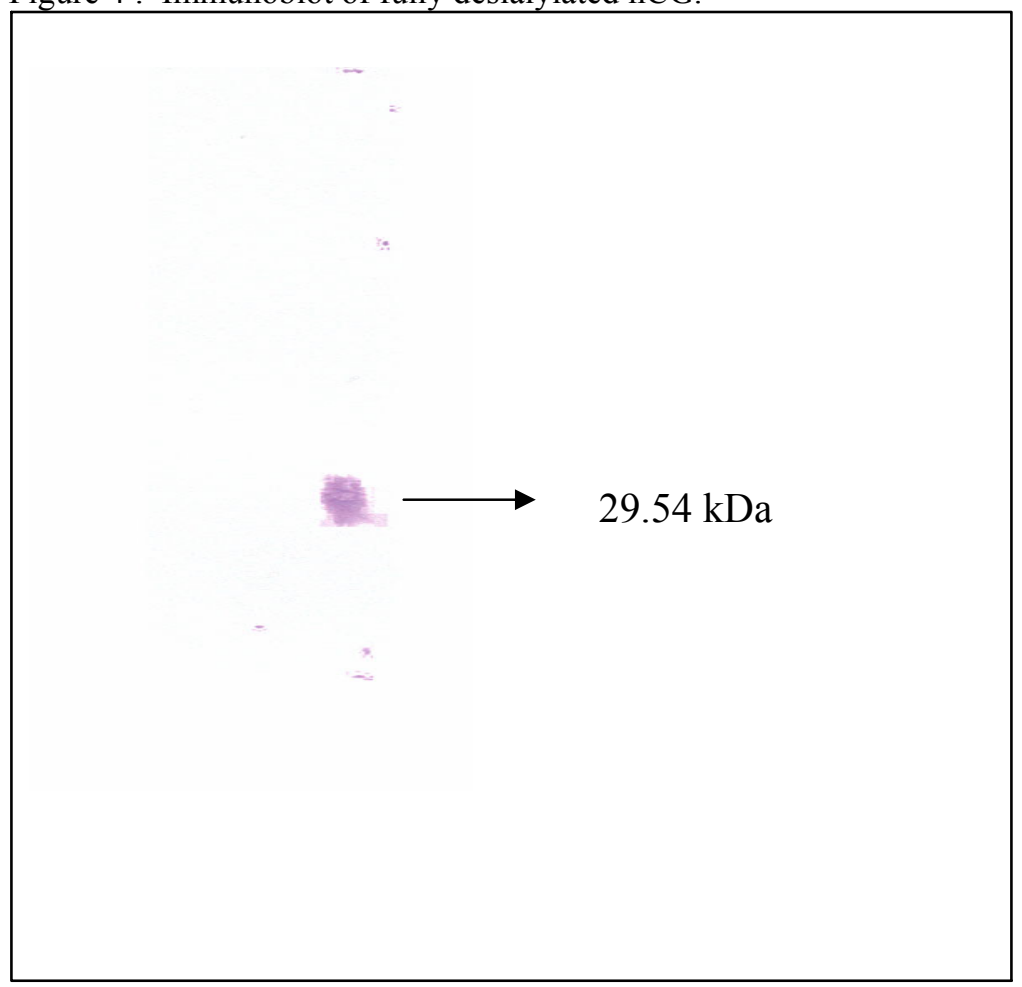

Figure 5: Chromatogram of hCG separated by HPLC and detected at $220 \mathrm{~nm}$ wavelength.

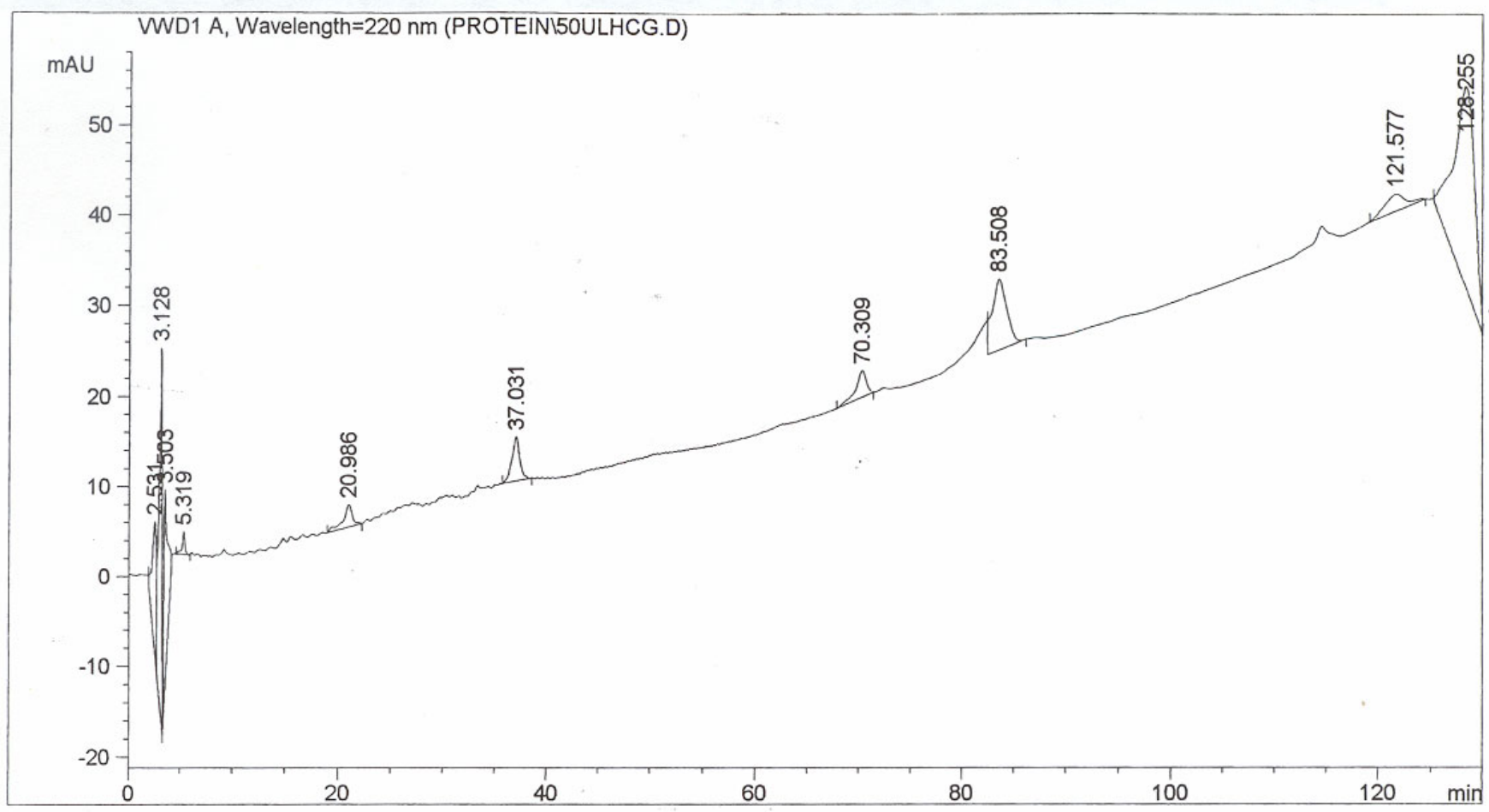


Figure 6: Immunoblot of hCG isolated from the HPLC separation; each lane were loaded with fraction that was collected at different retention times, lane 1: fraction collected at 5.3 minute retention time, lane 2: 14.1 minute, lane 3: 15.3 minutes, lane 4:20.9 minute, lane 5: 24.2 minute, lane 6: 37.0 minutes, lane 7: 70.3 minutes, lane 8: 83.5, lane 9: 114.6 minute and lane 10: 121.5 minute.

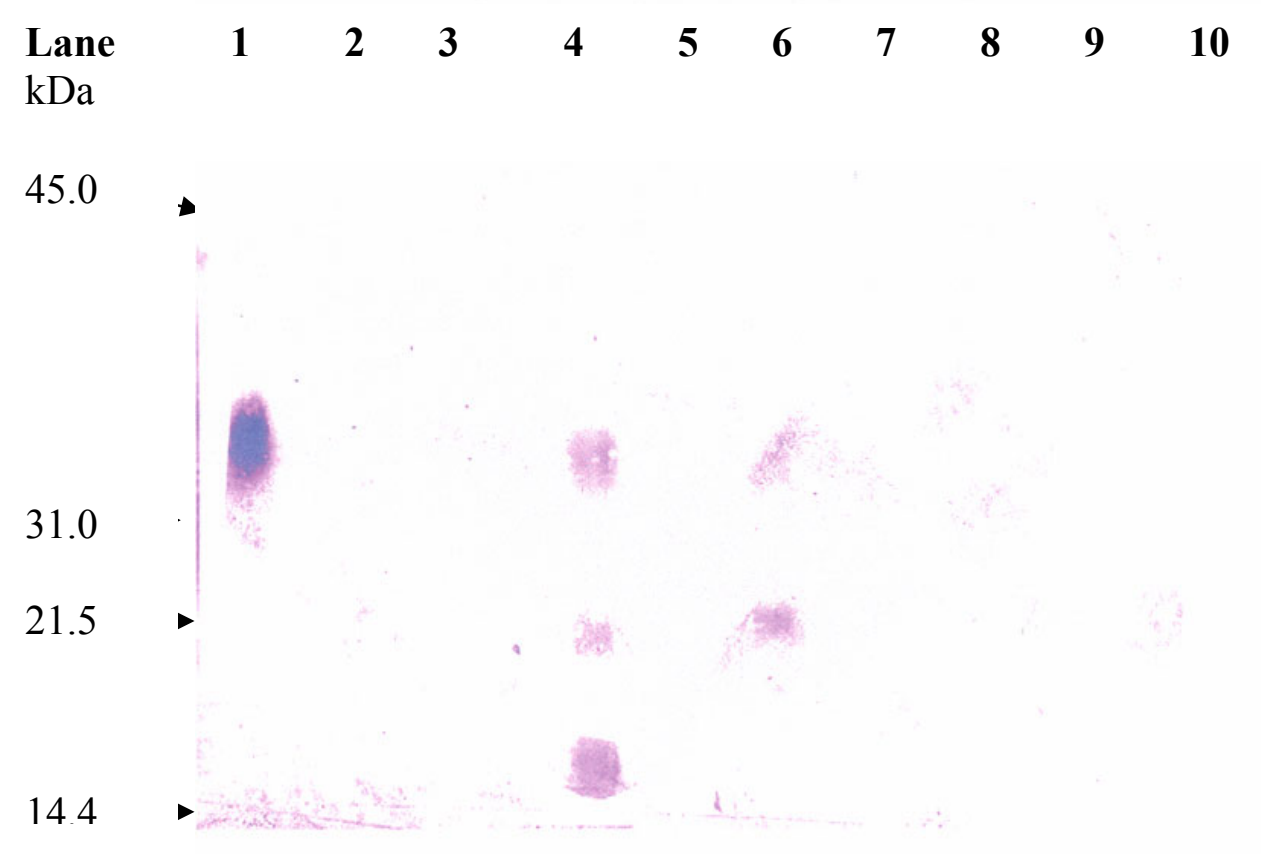

